\title{
Experimental and numerical analysis of residual stress in carbon-stabilized expanded austenite
}

Peng, Yawei; Liu, Zhe; Jiang, Yong; Wang, Bo; Gong, Jianming; Somers, Marcel A. J.

Published in:

Scripta Materialia

Link to article, DOI:

10.1016/j.scriptamat.2018.08.006

Publication date:

2018

Document Version

Peer reviewed version

Link back to DTU Orbit

Citation (APA):

Peng, Y., Liu, Z., Jiang, Y., Wang, B., Gong, J., \& Somers, M. A. J. (2018). Experimental and numerical analysis of residual stress in carbon-stabilized expanded austenite. Scripta Materialia, 157, 106-109.

https://doi.org/10.1016/j.scriptamat.2018.08.006

\section{General rights}

Copyright and moral rights for the publications made accessible in the public portal are retained by the authors and/or other copyright owners and it is a condition of accessing publications that users recognise and abide by the legal requirements associated with these rights.

- Users may download and print one copy of any publication from the public portal for the purpose of private study or research.

- You may not further distribute the material or use it for any profit-making activity or commercial gain

- You may freely distribute the URL identifying the publication in the public portal 
${ }^{*}$ Graphical Abstract

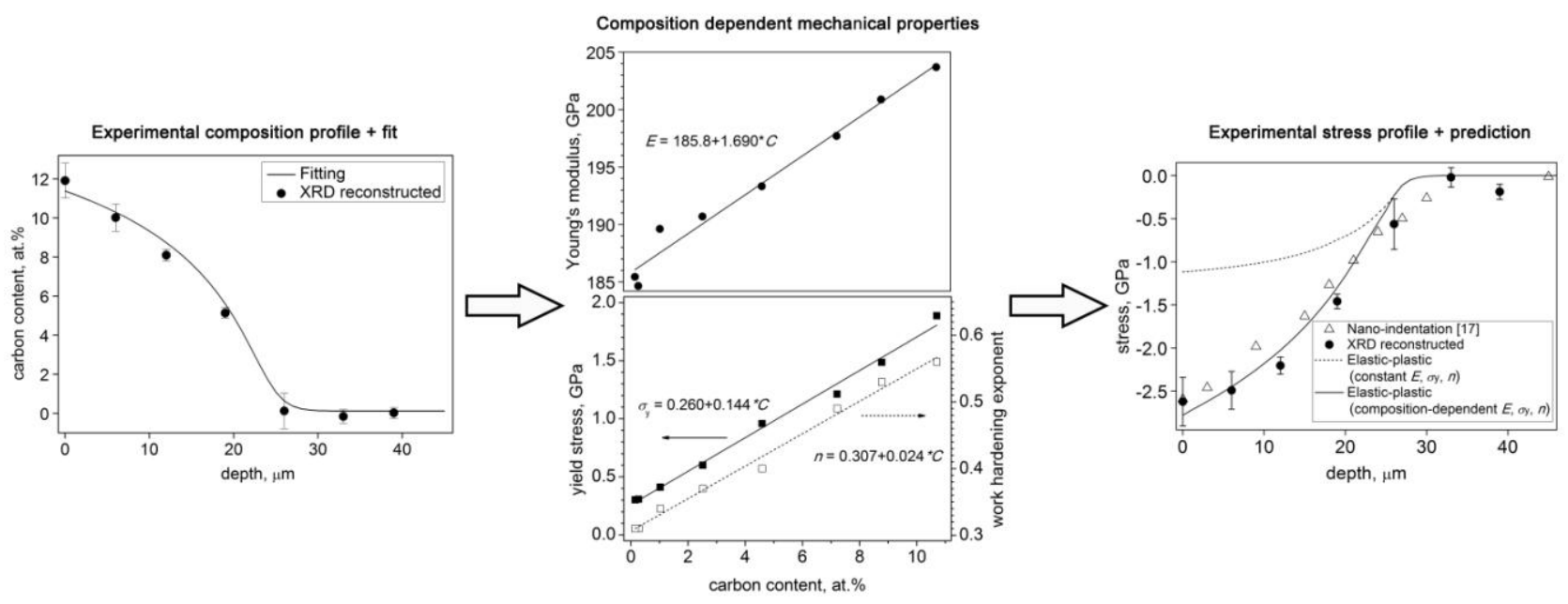




\title{
Experimental and numerical analysis of residual stress in carbon-stabilized expanded austenite
}

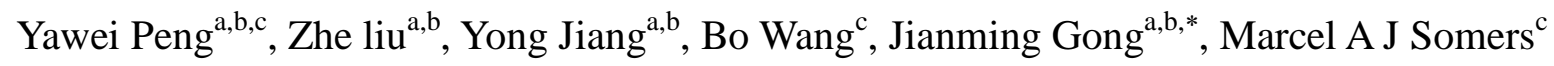 \\ ${ }^{a}$ School of Mechanical and Power Engineering, Nanjing Tech University, No.30 Puzhu South Road, \\ Nanjing 211816, China \\ ${ }^{\mathrm{b}}$ Jiangsu Key Lab of Design and Manufacture of Extreme Pressure Equipment, No.30 Puzhu South \\ Road, Nanjing 211816, China \\ ${ }^{\mathrm{c}}$ Department of Mechanical Engineering, Technical University of Denmark, Produktionstorvet b. 425, \\ 2800 Kgs. Lynby, Denmark
}

\begin{abstract}
Expanded austenite obtained by gaseous carburizing of stainless steel was investigated with X-ray diffraction to determine composition-depth and residual stress-depth distributions. Avoiding ghost stress effects in the analysis of X-ray diffraction data, the obtained composition- and stress-depth profiles are in excellent quantitative agreement with those obtained with other techniques. The residual stress-depth profile was attempted calculated from the composition-depth profile assuming elastic-plastic accommodation of the lattice expansion. In the model, composition-dependence of Young's modulus, yield stress and work hardening exponent were considered. Excellent quantitative agreement was achieved between the experimental and numerical residual stress-depth profiles.
\end{abstract}

Keywords: Expanded austenite; Surface treatment; Residual stress; X-ray diffraction; Numerical analysis

\footnotetext{
${ }^{*}$ Corresponding author. Tel: +862558139361 ; fax: +862558139361

E-mail addresses: gongim@njtech.edu.cn (J. Gong)
} 
Low-temperature thermochemical surface engineering of austenitic stainless steels through carburizing $(<800 \mathrm{~K})$, nitriding or nitrocarburizing $(<715 \mathrm{~K})$ has been demonstrated to significantly improve the tribological/wear and fatigue performance, as well as improving the resistance against localized corrosion [1-7]. The origin of these improvements is a case of expanded austenite, which essentially is a supersaturated solid solution of interstitial carbon or nitrogen atoms in austenite $[8,9]$. Although the present work concentrates on carbon-stabilized expanded austenite, the case developing on nitriding and nitrocarburizing is analogous; the main difference is that nitrogen can reach a substantially higher supersaturated solid solubility in austenite, because of the stronger interaction of $\mathrm{Cr}$ with $\mathrm{N}$ than with $\mathrm{C}$ atoms [10]. After low-temperature surface carburizing and nitriding, compressive residual stresses of several GPa's are present in the developed case. Due to the shallow case depth (few tens of microns) and the change from several GPa's compression to virtually zero stress over the case depth, it is challenging to accurately determine the quantitative values of the residual stresses. The X-ray diffraction (XRD) $\sin ^{2} \psi$ method is a widely applied technique to determine residual stresses by measuring the lattice strains and was also applied to carbon-stabilized expanded austenite $[7,8,11-13]$. Generally, for thermochemical surface engineering characterized by 1-dimensional (in depth) diffusion into a flat sample, the stress state is plane stress $\left(\sigma_{13}=\sigma_{23}=\sigma_{33}=\right.$ $0)$ and rotationally symmetric $\left(\sigma_{11}=\sigma_{22}=\sigma_{/ /}\right)$. Lattice strains $\varepsilon_{\psi}^{h k l}$ experienced by the set of lattice planes $\{h k l\}$ in a direction defined by tilt angle $\psi$ is given by [14]:

$$
\varepsilon_{\psi}^{h k l}=\frac{d_{\psi}^{h k l}-d_{\varepsilon=0}^{h k l}}{d_{\varepsilon=0}^{h k l}}=\frac{1}{2} S_{2}^{h k l} \sigma_{/ /} \sin ^{2} \psi+2 S_{1}^{h k l} \sigma_{/}
$$

where $d_{\psi l}^{h k l}$ and $d_{\varepsilon=0}^{h l l}$ are the strained and strain-free (reference) lattice spacings, respectively. $S_{1}^{h k l}$ and $\frac{1}{2} S_{2}^{h l l}$ are the X-ray elastic constants. 
Consequently, the lattice spacing along the depth-direction $z$ can be expressed as:

$$
d_{\psi}^{h k l}(z)=d_{\varepsilon=0}^{h k l}(z)\left[1+\sigma_{/ /}(z)\left(\frac{1}{2} S_{2}^{h k l} \sin ^{2} \psi+2 S_{1}^{h k l}\right)\right]
$$

Taking $K$ as the slope of $d_{\psi}^{h k l} v s \sin ^{2} \psi$ plots, the stress-depth profile can be straightforwardly calculated as :

$$
\sigma_{/ /}(z)=\frac{K}{\frac{1}{2} S_{2}^{h k l} d_{\varepsilon=0}^{h k l}(z)}
$$

where $d_{\varepsilon=0}^{h k l}(z)$ follows from inserting $\sin ^{2} \psi_{\varepsilon=0}=-2 S_{1}^{h k l} / \frac{1}{2} S_{2}^{h k l}$ in Eq.(2).

It should be noted that the lattice spacings determined by XRD analysis represent an intensity-weighted average value over the diffracting volume below the surface and depends on the geometry of the diffraction set up (Bragg angle 2 $\theta$, tilt angle $\psi$, and, optionally, a grazing incidence angle) and the combination of sample composition and applied wavelength. Straightforward application of the $\sin ^{2} \psi$ method without taking the stress and, in particular, composition gradients within the sampled volume into consideration, leads to artifacts in the determined stress values, so-called ghost stresses [15]. To avoid ghost stresses, Somers et al. [15,16] proposed a procedure where the actual residual stress profile is evaluated after reconstruction of the lattice spacing profiles for each of the $\psi$ directions investigated and was applied to carburized stainless steel in Ref. 9. Rong et al. [17] determined residual stresses in the low-temperature carburized case based on a nano-indentation technique proposed by Suresh et al. [18]. This method is more complicated compared to XRD method, but it does not lead to ghost stresses. Alternatively, numerical analysis can be applied to predict residual stresses in expanded austenite. A first attempt to numerically predict residual stresses in expanded austenite from elastic-plastic accommodation of the composition-induced lattice expansion was recently put forward by Jespersen et al. [19]. 
Fe) was treated by low-temperature gaseous carburizing at $743 \mathrm{~K}$ for $30 \mathrm{~h}$. Details of the low-temperature gaseous carburizing process were described elsewhere [20]. Residual stresses were determined by the PROTO-iXRD residual stress analyzer using the $\sin ^{2} \psi$ method with $\mathrm{Mn} \mathrm{K}_{\alpha}$ X-radiation $(\lambda=0.210314 \mathrm{~nm})$. Lattice strains were probed for the 311 austenite reflection, because this $h k l$ is least sensitive for plastic deformation in lattice strain determination [21]. The applied X-ray elastic constants were $S_{1}^{311}=-1.76 \times 10^{-6} \mathrm{MPa}^{-1}, \frac{1}{2} \mathrm{~S}_{2}^{311}=7.07 \times 10^{-6} \mathrm{MPa}^{-1}$ [9] and assumed independent of the composition. Five $\omega$ tilt angles were applied corresponding with $\sin ^{2} \psi$ values ranging from 0 to 0.4 . For depth profiling, thin layers were successively removed by careful grinding and polishing unto a final step of $3.5 \mu \mathrm{m}$ diamond paste. In order to avoid ghost stresses, the method firstly proposed in Ref. 15, was applied, involving:

(1) The experimental assessment of $\left\langle d_{\psi}^{h k l}(\Delta z)\right\rangle$ vs. $\Delta z$ profiles, where $\Delta z$ is the total thickness removed.

(2) Reconstruction of $d_{\psi}^{h k l}(z)$ profiles for all investigated values of $\psi$ from $\left\langle d_{\psi}^{h k l}(\Delta z)\right\rangle v s \Delta z$ profiles:

$$
\left.d_{\psi}^{h k l}(z)\right|_{x=y}=\left\langle d_{\psi}^{h k l}(\Delta z)\right\rangle-\left.\frac{\partial\left\langle d_{\psi}^{h k l}(\Delta z)\right\rangle}{\partial z}\right|_{y} \cdot\left[\frac{1-\exp \left(-A_{\psi} \cdot\left(Z_{1}-\Delta z\right)\right)}{A_{\psi}}\right]
$$

where $Z_{1}$ is the (original) layer thickness for the case where layer and substrate can be distinguished with XRD. If layer and substrate cannot be distinguished by $X R D, Z_{1}$ should be replaced by half the sample thickness (for expanded austenite, $Z_{1}$ is the sample thickness, i.e., effectively infinitely large). $A_{\psi}$ is the absorption factor for the X-ray diffraction geometry under consideration. For an $\Omega$-type goniometer as applied here, the absorption factor is:

$$
{ }^{\Omega} A_{\psi}=\mu\left[\frac{1}{\sin (\theta+\psi)}+\frac{1}{\sin (\theta-\psi)}\right]
$$


where $\mu$ is the linear absorption coefficient of the X-radiation used in the sample investigated, which was taken as $0.075 \mu \mathrm{m}^{-1}$.

(3) Reconstruction of $d_{\psi}^{h k l}$ vs. $\sin ^{2} \psi$ plots at the various depths $z$ and determination of the strain-free lattice parameter $d_{\varepsilon=0}^{h k l}(z)$ for the strain-free direction and calculation of the stress from Eq. (3).

The composition-depth and residual stress-depth profiles thus determined are given in Fig.1. For comparison also the profiles obtained without appropriate reconstruction are given. Evidently, the reconstructed carbon contents and compressive residual stress values are much larger than the "uncorrected" values; in the steepest part of the profiles an underestimation of the composition and stress by up to $1.72 \% \mathrm{C}$ and $1.0 \mathrm{GPa}$, respectively, results if no appropriate data evaluation is made. For comparison the composition profile obtained by electron probe microanalysis (EPMA) [22] and the residual stress-depth profile obtained by Rong et al. [17] with nano-indentation for a sample carburized under identical conditions, are given in Fig. 1 for comparison. Excellent agreement is obtained between the independent techniques. After reconstruction, a maximum compressive residual stress of $-2.65 \mathrm{GPa}$ is obtained at the surface, for a maximum carbon content of 11.7 at.\% C; similar values were found in Ref. 9 for gaseously carburized AISI 316, albeit under different conditions. Clearly, the determined residual stress values are beyond the uniaxial yield stress of AISI 316L (292 $\pm 5 \mathrm{MPa}$, as measured in uniaxial tension). It should be noted that the dissolution of carbon atoms in the austenite lattice contributes appreciably to strengthening of the lattice [23]. In previous work, it was found that the Young's modulus, $E$, yield stress, $\sigma_{y}$, and work hardening exponent, $n$, assessed (at room temperature) by nano-indentation all depend on the carbon content in expanded austenite [24]. The data showing the composition dependence is summarized in Fig. 2. Although, the yield strength is enhanced spectacularly, eventually the competition between strengthening by carbon 
dissolution and composition-induced stress leads to plastic deformation (see also discussion in Ref. 9, where this was already pointed out). This is consistent with the observation of extensive slip bands at the surface of austenitic stainless steel after low-temperature surface carburizing [7,25].

During low-temperature carburizing no phase transformation occurs [8]. Although carbon is expected to have some effect on the thermal expansion coefficient of austenite, this effect is negligible as long as no magnetic transition occurs on cooling [26]. Therefore, the total strain $\varepsilon_{i j}^{\text {tof }}$ in the carburized sample is the sum of the mechanical strain $\varepsilon_{i j}^{\text {mech }}$ and the composition-induced strain $\varepsilon_{i j}^{\mathrm{c}}$, which is given by:

$$
\varepsilon_{i j}^{\mathrm{tot}}=\varepsilon_{i j}^{\mathrm{el}}+\varepsilon_{i j}^{\mathrm{pl}}+\varepsilon_{i j}^{\mathrm{c}}
$$

where the mechanical strain is the sum of the elastic strain $\varepsilon_{i j}^{\mathrm{el}}$ and plastic strain $\varepsilon_{i j}^{\mathrm{pl}}$.

The composition-induced strain arising from the expansion of the austenite lattice as caused by dissolution of carbon atoms is defined as:

$$
\begin{array}{lc}
\text { for } i=j: & \varepsilon_{i j}^{\mathrm{c}}(C)=\frac{a(C)-a_{0}}{a_{0}} \\
\text { for } i \neq j: & \varepsilon_{i j}^{\mathrm{c}}(C)=0
\end{array}
$$

where $a(\mathrm{C})$ is the composition-dependent lattice parameter of unstrained expanded austenite and $a_{0}$ is the lattice parameter of the untreated sample. The composition-dependent lattice parameter of expanded austenite (at room temperature ${ }^{1}$ ) is given by $a(C)=0.35965+0.06029 y_{\mathrm{C}}$ (in nm) [27], where $y_{\mathrm{C}}=C /(100-C)$ is the site fraction.

In the sequel the procedure for calculating elastic and plastic stresses as firstly applied by Jespersen et al. [19] to nitrogen-stabilized expanded austenite is followed. For the case of the elastic-plastic accommodation of the lattice expansion, the stress depends on the loading path. The

1 The strain applies at the carburizing temperature, but since the thermal expansion coefficient is virtually constant in the composition range under consideration, the strains can be calculated from the room temperature lattice parameters. 
relation between the incremental mechanical stress $d \sigma_{i j}^{\text {mch }}$ and the incremental mechanical strain $d \varepsilon_{i j}^{\text {mech }}$ can be expressed as [28]:

$$
d \sigma_{i j}^{\text {mech }}=L_{i j k l} d \varepsilon_{k l}^{\text {mech }}
$$

where $L_{i j k l}$ is the incremental stiffness tensor, which is given according to $J_{2}$-flow theory [28]:

$$
L_{i j k l}=\frac{E}{1+v}\left[\frac{1}{2}\left(\delta_{i k} \delta_{j l}+\delta_{i l} \delta_{j k}\right)+\frac{v}{1-2 v} \delta_{i j} \delta_{k l}-\alpha \frac{3}{2} \frac{E / E_{t}-1}{E / E_{t}-(1-2 v) / 3} \frac{s_{i j} s_{k l}}{\sigma_{\mathrm{v}}{ }^{2}}\right]
$$

where $\delta_{i j}$ is Kronecker's delta. $E$ and $E_{\mathrm{t}}$ are Young's modulus and tangent modulus, respectively; $v$ is Poisson's ratio; $s_{i j}$ is the stress deviator tensor and $\sigma_{\mathrm{v}}$ is the von Mises stress; $\alpha=0$ if there is pure elasticity and $\alpha=1$ if there is plastic flow. For further details of the application of the $\mathrm{J}_{2}$-flow theory on expanded austenite, see Jespersen et al. [19].

Before calculation of the composition-induced residual stresses, the carbon concentration should be calculated as input data. Both Hummelshøj et al. [29]. and Ernst et al. [30] found that the carbon diffusivity depends strongly on the carbon content in expanded austenite. Therefore, Fick's $1^{\text {st }}$ law with composition-dependent diffusivity was applied to simulate the carbon content-depth profile, which can be expressed as [31]:

$$
J=-D \exp \left(k \frac{C}{C_{\max }}\right) \frac{\partial C}{\partial x}
$$

where $J$ is diffusion flux; $C_{\max }$ is the maximum possible concentration; $k$ controls the magnitude of the c dependence; $D$ is the diffusivity of $\mathrm{C}$ for infinite dilution.

Thus, Fick's $2^{\text {nd }}$ law can be written as:

$$
\frac{\partial C}{\partial t}=D \frac{k}{C_{\max }} \exp \left(k \frac{C}{C_{\max }}\right)\left(\frac{\partial C}{\partial x}\right)^{2}+D \exp \left(k \frac{C}{C_{\max }}\right) \frac{\partial^{2} C}{\partial x^{2}}
$$

where $t$ is the carburizing time.

The surface concentration $C_{\mathrm{s}}$ of the sample during low-temperature surface carburizing depends 
on the balance of the carbon fluxes arriving $J_{\mathrm{s}}$ at and leaving $J_{\mathrm{s}}$ ' from the surface. Thus, an additional boundary condition can be expressed as:

$$
\frac{\partial C_{\mathrm{s}}}{\partial t}=-\frac{J_{\mathrm{s}}^{\prime}-J_{\mathrm{s}}}{\Delta x}=\frac{\beta \cdot\left(C_{\mathrm{eq}}-C_{\mathrm{s}}\right)+D \exp \left(k \frac{C_{\mathrm{s}}}{C_{\text {max }}}\right) \frac{\partial C_{\mathrm{s}}}{\partial x}}{\Delta x}
$$

where $\Delta x$ is the step of depth; $\beta$ is the mass transfer coefficient; $C_{\text {eq }}$ is the carbon concentration in the solid-phase that would prevail if the imposed equilibrium is attained between carbon in the gas-phase and carbon in solid solution. The sample is considered infinitely thick as compared to the case depth.

In the present analysis the role of stress on the composition profile, i.e. the pressure effect on the carbon solubility and diffusivity as well as the additional driving force for diffusion arising from a stress gradient [19,32], were not considered. Rather than an accurate prediction of the kinetics of the growth of the expanded austenite case, the main purpose of applying Eqs. (11) and (12) is to obtain an effective mathematical description of the experimental concentration profile as input for calculating the composition-induced residual stresses. To implement the diffusion model, $D=1.9 \times$ $10^{-5} \exp (-18833 / T)$ [33], corresponding to $D=1.74 \times 10^{-16} \mathrm{~m} \cdot \mathrm{s}^{-1}$ at the carburizing temperature of $743 \mathrm{~K} ; C_{\max }=C_{\mathrm{eq}}=12.8$ at. $\%$ and $\beta=8 \times 10^{-10} \mathrm{~m} \cdot \mathrm{s}^{-1}$ [22]; $k$ is taken as a fit parameter. The best fit was obtained for $k=4.2$. Fig. 3 (top) shows the experimentally determined and calculated concentration-depth profile of carbon in low-temperature surface carburized AISI 316L.

Assuming elastic-plastic accommodation of the lattice expansion, the composition profile from Fig.3 (top) was used to calculate the residual stress-depth profiles given in Fig. 3 (bottom). Considering composition-independent elastic and plastic properties, the level of the calculated residual stress is too low as compared to the experimental value, which maximum compressive residual stress is only $-1.1 \mathrm{GPa}$ at the surface. Incorporating the composition-dependence of the 
elastic and plastic mechanical properties (cf. Fig.2) into the elastic-plastic accommodation of the composition-induced lattice expansion provides an excellent agreement with the experimentally determined residual stress-depth profile. Currently, the temperature dependence of the mechanical properties was not taken into consideration, because no experimental data is available.

Summarizing, the XRD $\sin ^{2} \psi$ method combined with successive layer removal results in composition-depth and residual stress-depth distributions in excellent agreement with results obtained by independent techniques, provided that an appropriate avoidance of ghost stresses is performed. After appropriate correction, a maximum residual stress in the carburized AISI 316L up to $-2.65 \mathrm{GPa}$ is obtained at the surface, while the carbon content reached 11.7 at.\%. Residual stress-depth profiles were numerically predicted from the composition-induced lattice expansion, under the assumption of elastic-plastic accommodation. In this prediction it is crucial to take the composition-dependent Young's modulus, yield stress and work hardening coefficient in to account. Then, excellent quantitative agreement between the experimental residual stress-profiles is achieved.

The work is supported by China Scholarship Council, National Natural Science Foundation of China (No 51475224), Natural Science Foundation of Jiangsu Higher Education Institutions of China (No 14KJA470002) and Innovation Project for College Graduates of Jiangsu Province (No KYZZ16_0234).

\section{Reference}

[1] J. Qu, P.J. Blau, B.C. Jolly, Wear, 263 (2007) 719-726.

[2] L. Ceschini, C. Chiavari, E. Lanzoni, C. Martini, Mater. Design, 38 (2012) 154-160.

[3] Z.L. Zhang, T. Bell, Surf. Eng. 1 (1985) 131-136.

[4] N. Agarwal, H. Kahn, A. Avishai, G. Michal, F. Ernst, A.H. Heuer, Acta Mater. 55 (2007) 
$5572-5580$.

[5] T.L. Christiansen, M.A.J. Somers, Int. J. Mater. Res. 100 (2009) 1361-1377.

[6] A.H. Heuer, H. Kahn, F. Ernst, G.M. Michal, D.B. Hovis, R.J. Rayne, F.J. Martin, P.M. Natishan, Acta Mater. 60 (2012) 716-725.

[7] Y. Peng, C. Chen, X. Li, J. Gong, Y. Jiang, Z. Liu, Surf. Coat. Technol. 328 (2017) 420-427.

[8] G.M. Michal, F. Ernst, Y. Cao, F. Oba, N. Agarwal, A.H. Heuer, Metall. Mater. Trans. A 54 (2006) 1597-1606.

[9] T. Christiansen, M.A.J. Somers, Metall. Mater. Trans. A 37 (2006) 675-682.

[10] T. Christiansen, M.A.J. Somers, Surf. Eng. 21 (2005) 445-455.

[11] T.L. Christiansen, M.A.J. Somers, Metall. Mater. Trans. A 40 (2009) 1791-1798.

[12] Y. Sun, L.Y. Chin, Surf. Eng. 18 (2013) 443-446.

[13] S. Thaiwatthana, N. Jantaping, P. Limthongkul, Surf. Eng. 28 (2012) 273-276.

[14] H. Dölle, J. Appl. Crystallogr. 12 (1979) 489-501.

[15] M.A.J. Somers, E.J. Mittemeijer, Metall. Trans. A 21A (1990) 189-204.

[16] T. Christiansen, M.A.J. Somers, Mater. Sci. Eng. A 424 (2006) 181-189.

[17] D. Rong, Y. Jiang, J. Gong, Mater. Sci. Technol. 33 (2016) 227-284.

[18] S. Suresh, A.E. Giannakopoulos, Acta Mater. 46 (1998) 5755-5767.

[19] F.N. Jespersen, J.H. Hattel, M.A.J. Somers, Modelling Simul. Mater. Sci. Eng. 24 (2016) 025003.

[20] Y. Peng, J. Gong, Y. Jiang, M. Fu, D. Rong, Surf. Coat. Technol. 304 (2016) 16-22.

[21] B. Clausen, T. Lorentzen, T. Leffers, Acta Mater. 46 (1998) 3087-3098.

[22] Y. Peng, J. Gong, C. Chen, Z. Liu, Y. Jiang, Metals 8 (2018) 214.

[23] A.H. Heuer, F. Ernst, H. Kahn, A. Avishai, G.M. Michal, D.J. Pitchure, R.E. Ricker, Scripta Mater. 56 (2007) 1067-1070.

[24] Y. Jiang, Y. Li, Y. Jia, X. Chen, J. Gong, Acta Metall. Sin. (Engl. Lett.) 90 (2018) 1-11.

[25] S.C. Gallo, H. Dong, Appl. Surf. Sci. 258 (2011) 608-613.

[26] B.K. Brink, Ph.D. Thesis, Technical University of Denmark, June 2015.

[27] T.S. Hummelshøj, T.L. Christiansen, M.A.J. Somers, Scripta Mater. 63 (2010) 761-763.

[28] V. Tvergaard, J. Mech. Phys. Solids 24 (1976) 291-304.

[29] T.S. Hummelshøj, T.L. Christiansen, M.A.J. Somers, Defect Diffus. Forum 273-276 (2008) 306-311. 
[30] F. Ernst, A. Avishai, H. Kahn, X. Gu, G.M. Michal, A.H. Heuer, Metall. Mater. Trans. A 40 (2009) 1768-1780.

[31] J. Crank, The mathematics of diffusion, Clarendon Press, Oxford, 1956, pp. 172.

[32] T.L. Christiansen, M.A.J. Somers, Defect Diffus. Forum 297-301 (2010) 1408-1413.

[33] X. Gu, Ph.D. Thesis, Case Western Reserve University, May 2011. 


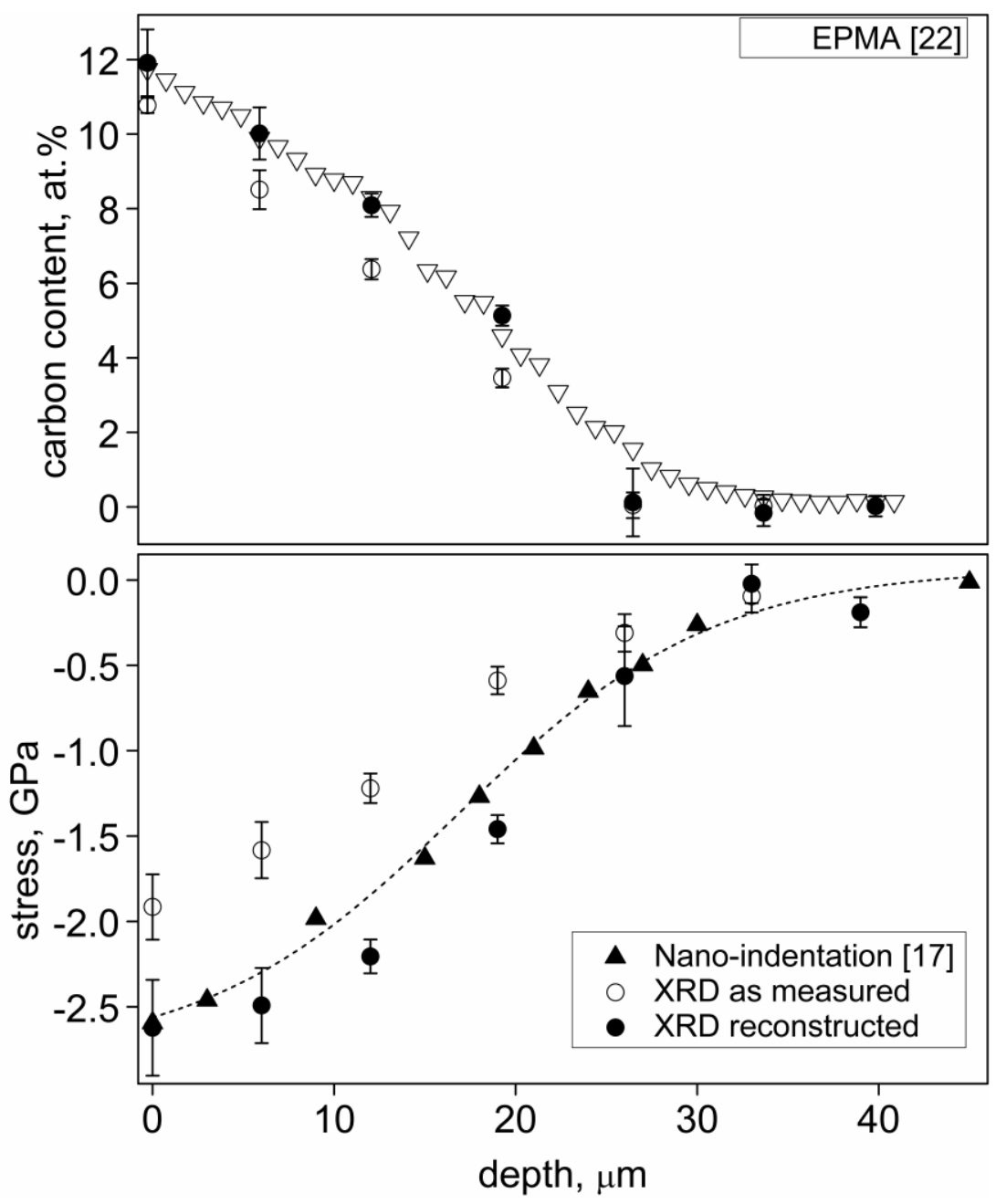

Fig. 1. Experimental composition-depth and residual stress-depth profiles of AISI 316L carburized at $743 \mathrm{~K}$ for $30 \mathrm{~h}$, determined with XRD analysis with and without ghost stress correction, EPMA and nano-indentation (EPMA data from Ref. 22 and nano-indentation data from Ref. 17). The dashed line is a sigmoidal fit through the nano-indentation data. 


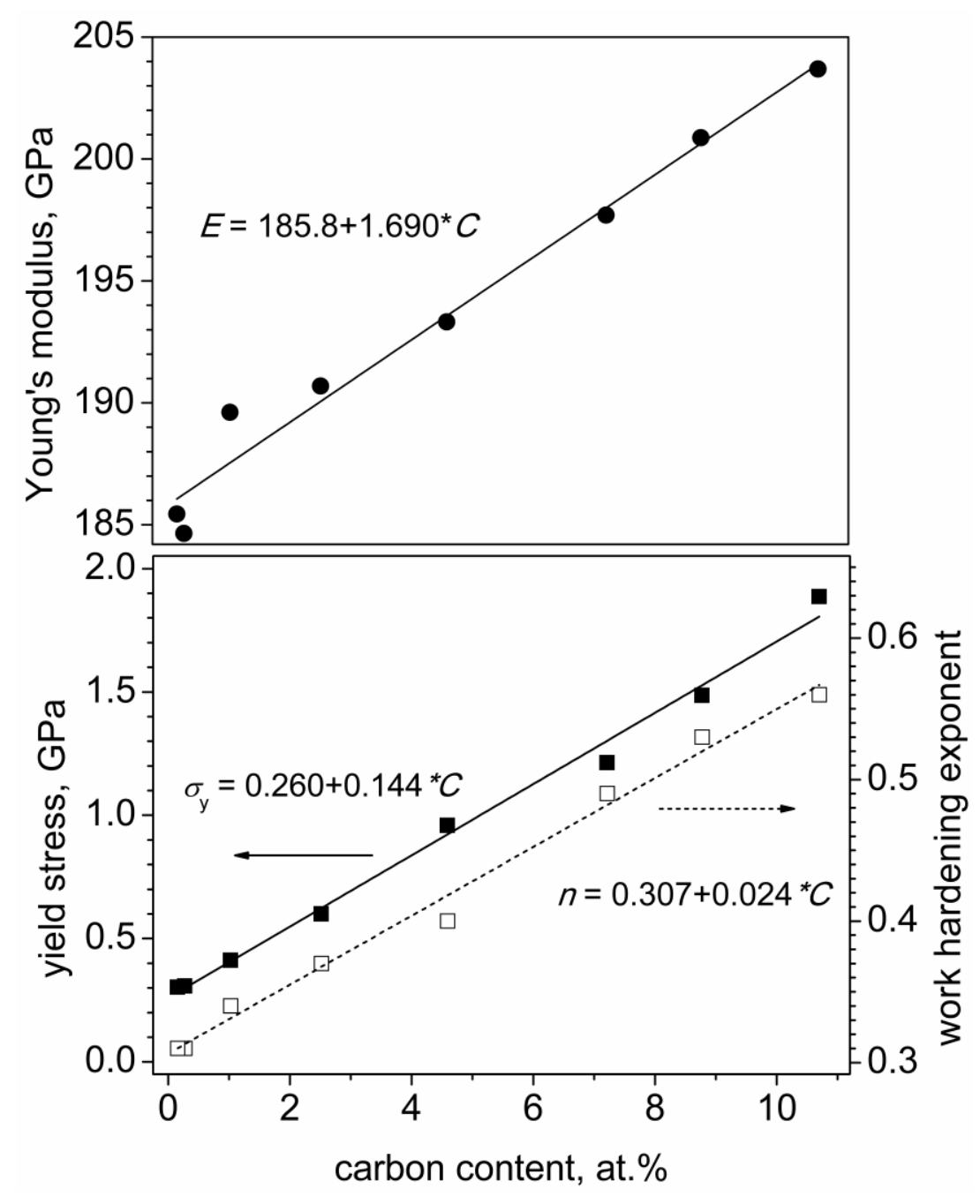

Fig. 2. Young's modulus, yield stress and work hardening exponent of expanded austenite as a function of carbon content (data from Ref. 24). 


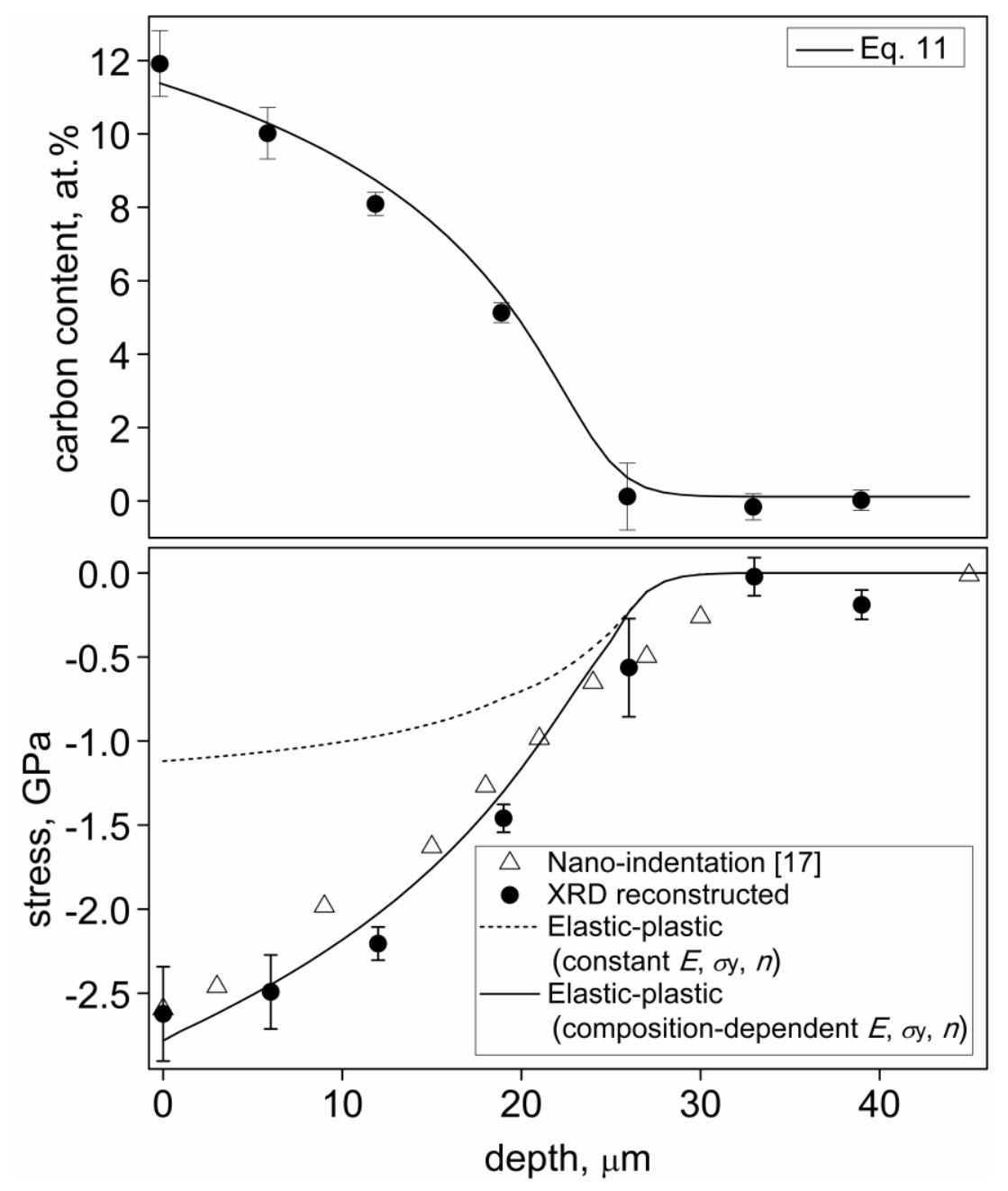

Fig. 3. Experimental and fitted composition-depth profiles (top) and experimental and predicted residual stress-depth profiles (bottom) assuming elastic-plastic accommodation of the lattice expansion of low-temperature carburized AISI 316L. 